\title{
Applying mathematics in real-life problems: A case study of two senior high schools in Ghana
}

\author{
Fletcher ${ }^{11}$, J. A.
}

\begin{abstract}
The purpose of this exploratory study was to investigate the extent to which senior high school students could apply mathematics in real life situations by examining the relationship between their performance on "routine" mathematical calculations and that on a "shortwriting" task related to the application of mathematics. It involved thirty boys and thirty girls from two Senior High Schools in Accra, the capital of Ghana in West Africa. All the sixty participants were in Form 1 (SHS1) at the time of the study. Data for the study was collected between June and August 2008 using tasks and interviews. Both qualitative and quantitative analytical techniques were used to analyse the data. The results of the study showed no significant gender differences in the students' performance on both the routine and the short-writing tasks but showed marked differences between the students' performance on the routine calculations and that on the short-writing task. The students' mean score for the routine calculations was significantly higher than their mean score for the short-writing task as the difference between the two mean scores was statistically significant at the $0.1 \%$ level. Furthermore, there was a strong correlation between the students' performance on the two different tasks. The implications of the results for the teaching and learning of mathematics are discussed.
\end{abstract}

Keywords problem-solving, application, routine, task-oriented

\section{Introduction}

Employers and educators have identified mathematics as vital for enabling young people and adults to develop the practical skills to succeed in further learning, employment and life in modern society. Indeed, the importance of mathematics has been underscored in many mathematics education reports. For example, the Adrian Smith Report into post-14 mathematics education highlighted the importance of the subject for its own sake:

Mathematics provides a powerful universal language and intellectual toolkit for abstraction, generalization and synthesis. It is the language of science and technology. It enables us to probe the natural universe and to develop new technologies that have helped us control and master our environment, and change societal expectations and standards of living. Mathematical skills are highly valued and sought after. Mathematical training disciplines the mind, develops logical and critical reasoning, and develops analytical and problem solving skills to a high degree. (Smith, 2004, p.10).

The report goes on to outline the uses of mathematics in different areas of endeavour including the economy, science and technology and the world of work. On worlds of work, the report noted:

Major employers in the engineering, construction, pharmaceutical, financial and retail sectors have all made [it] clear to us their continuing need for people with appropriate mathematical skills. In particular, employers highlight the shortage of statisticians. Advanced economies need an increasing number of people with more than minimum qualifications in mathematics to stay ahead in international competitiveness and, in particular, to effectively exploit advances in technology. An adequate supply

${ }^{11}$ Dr. Jonathan A. Fletcher is a senior lecturer in mathematical education at the University of Cape Coast, and a visiting lecturer to the University of London. 
of young people with mastery of appropriate mathematical skills at all levels is vital to the future prosperity of the UK. (ibid, original emphasis).

In Ghana, the main rationale for the Senior High School (SHS) mathematics syllabus is "focused on attaining one crucial goal: to enable all Ghanaian young [people] to acquire the mathematical skills, insights, attitudes and values that they will need to be successful in their chosen careers and daily lives" (CRDD, 2007, p.ii). In other words, the SHS mathematics syllabus is designed to enable teachers to teach learners how to make sense of the world around them through developing learners' ability to do calculations, reason and solve problems. If this aim is to be achieved, then the mathematics curriculum should enable these learners to understand, among other things, relationships and patterns in number and space in their everyday lives.

Indeed, mathematics ought to equip learners with uniquely powerful ways to describe, analyse and change the world. It should and can stimulate moments of pleasure and wonder for all learners when they solve a problem for the first time, discover a more elegant solution, or notice hidden connections. Learners who are functional in mathematics are able to think independently in applied and abstract ways and can reason, solve problems and assess risks. The implication for teaching is that teachers should make mathematics functional to learners if the latter are to benefit fully from studying the subject.

The term "functional" here is considered in the broad sense of providing learners with the skills and abilities they need to take an active and responsible role in their communities. Functional mathematics requires learners to use mathematics in ways that make them effective and involved as citizens, operate confidently and to convey their ideas and opinions clearly in a wide range of contexts (QCA, 2007). In many advanced countries such as the United Kingdom (UK), the fundamentals of mathematics - often packaged with the fundamentals of language in the term 'literacy and numeracy' - have tended to be treated as a primary basic requirement for the overall population in order to raise productivity (DfES 2005; DIUS 2007, Leitch, 2006). It is therefore not surprising that the Royal Society (2008) considers that a solid grounding for all in mathematics "up to age 16 and, for the majority, further study at a level beyond General Certificate of School Examination (GCSE) Intermediate, is needed so...all can function effectively in their personal and professional lives" (p.4).

To build and apply mathematical functional skills, teachers will need to focus on applied learning by creating problem-solving opportunities using both small- and large-scale scenarios, and through activities that require pupils to think for themselves and to select which functional mathematical skills are required to succeed. Yet the way mathematics is assessed in junior and senior high schools in Ghana (mainly through timed written examinations) makes it difficult for teachers of mathematics to put the required emphasis on functional mathematics (Fletcher, 2001).

This situation is not only apparent in Ghana, for research suggests that this is the case in many countries. For example, Tomlinson (2004) observed that it is possible for young people in the UK to achieve grade $\mathrm{C}$ and above in GCSE mathematics without having a satisfactory standard of numeracy. This observation buttresses the findings of an earlier research by Hoyles et al (2002) in which the researchers examined the requirements for mathematical skills in the workplace. A key finding of that research was that although the ubiquitous use of information technology in all sectors had changed the nature of the mathematical skills required, it had not reduced the need for mathematics. Hoyles et al (op. cit.) refer to these mathematical skills and competencies, framed by the work situation and practice and the use of IT tools, as mathematical literacy. This clearly suggests that "traditional" school mathematical skills ought to be turned into work mathematical skills if the subject is to 
benefit young people and society at large. On the basis of detailed case studies, the research in question concluded that there is an increasing need for workers at all levels of organisations to possess an appropriate level of mathematical literacy. The cause of the apparent lack of mathematical literacy among workers who took part in the research was laid at the doorstep of teachers who do not make the 'conversion' between school mathematics and mathematical literacy clear to learners. It would appear that many mathematics teachers do not provide opportunities for learners to make this conversion successfully.

Verschaffel and de Corte (2000) have observed that one aspect of mathematical problem solving that is most disturbing in recent years is that researchers have found that, in some instances, school mathematics is taught in such a way that school children, after receiving instruction in mathematics, regard mathematics purely as an academic discipline divorced from real-world problem solving. Wu and Adams (2006) cite Nesher's study with grade five pupils in which the latter were given the following problem: "What will be the temperature of water in a container if you pour 1 jug of water at $80^{\circ} \mathrm{F}$ and 1 jug of water at $40^{\circ} \mathrm{F}$ into it?" Many children answered " $120^{\circ} \mathrm{F}$ "! In that study, many children were quite happy to give answers such as 5.2 buses or 8.4 balloons as they accurately carried out long divisions or multiplications. Termed "suspension of sense-making" by Schoenfeld (1991, p. 316), this phenomenon is widespread around the world (ibid).

Indeed, examples of failure to use basic problem solving skills in mathematics in real life situations abound. Another well known example, which Hughes et al (2000) cite, comes from a survey of mathematical understanding carried out in the Unites States of America in the 1980s. As part of the survey, 13-year old students were told that an army bus holds 36 soldiers and asked how many buses will be needed to transport 1128 soldiers to their training site. Most of the students knew they needed to do a division calculation and some of them divided 1128 by 36 to produce an answer of 31.33 and said that was the number of busses needed. Nearly a quarter of the students who participated in the study rounded the above figure to the nearest whole number and said 31 buses were needed, thus leaving 12 soldiers with no transport!

Clearly, people often show a very limited capacity to apply mathematics. One would argue that people who fail to apply mathematical concepts successfully have a rather weak grasp of the mathematical concepts involved but this is usually not the case. This was evident in the study of some Swedish 12- and 13-year olds who were gifted at basics mathematics (Säljö \& Wyndham 1990). In that study, the pupils were asked to find the cost of posting a letter. They were given a letter (which weighed 120 grams), some scales and a simple post office charge which indicated rates of postage. For example, letters up to 100 gram would cost 4 kronor, while letters up to 250 grams would cost 7.50 kronor. This is in fact a very simple problem, requiring the students to simply weigh the letter and read off the appropriate rate. However, many of the pupils failed to find the correct postage and most of them who succeeded did so after a great deal of trouble. The higher the mathematical attainment of the pupils, the more roundabout were their problem solving procedures. These students, it seems, had considerable difficulty in knowing which aspect of their classroom knowledge they should apply to solve the cost of postage problem. Even these gifted students showed severe limitations in their ability to transfer their classroom mathematical knowledge and skills from one context to another.

A further illustration of the problem of application comes from a study of Brazilian children's mathematical competences (Nunes, et al 1993). The children in the study were street traders in a large city in Brazil. Street trading is an economic necessity for large numbers of youngsters in Brazil. Nunes and her colleagues studied several of these children (with little or 
no schooling) in their working environment of their street stalls. The children's capabilities were first observed in normal trading transactions, for example:

$\begin{array}{ll}\text { Customer/researcher: } & \text { How much is one coconut } \\ \text { Trader: } & \text { Thirty-five } \\ \text { Customer: } & \text { l'd like ten. How much is that? } \\ \text { Trader: } & \text { (Pause) ...three will be one hundred and five,... with three more that will be } \\ & \text { two hundred and ten. (Pause ) I need four more. that is...(pause) three } \\ & \text { hundred and fifteen.....(pause). I think it is three hundred and fifty. (Nunes et } \\ & \text { al, op. cit, pp 18-19) }\end{array}$

In all 63 problems were set to five traders aged between 9 and 15 years. Overall, the traders had a success rate of 98 percent. Next, the same children were presented with formal arithmetic test. For these tests, the items were exactly the same as those met on the street except that they were reduced to arithmetic questions only. For example, instead of asking "What is the cost of 10 coconuts cost at 35 each?", the trader was given pencil and paper and asked to solve " $10 \times 35$ ". With these tests the children had difficulties doing the appropriate calculations. Their success rate fell from 98 percent in the mental arithmetic of the street to 37 percent in the pencil and paper test.

On the face of it, the Brazilian and Swedish children might seem to have the reverse problem to each other. The Brazilian children had difficulty transferring their street knowledge to the 'school test', while the Swedish children had trouble transferring their school mathematical knowledge and skills to real life problem solving. Put differently, both groups of children had difficulties in applying mathematical expertise learned in one setting to problems set in a different context.

Whichever way one looks at the above examples, they serve powerfully to illustrate a well known problem of mathematics education wherever it is fostered: students seem to have enormous difficulty in using and applying mathematical skills and knowledge from the instructions and formats in which they are learned to novel situations.

\section{Purpose of the study and research question}

The purpose of the present study was to explore the extent to which boys and girls in senior high schools could apply mathematical concepts to real life situations. It was hoped that the study would throw some light on how teachers were making use of learners' problem solving skills in mathematics lesson in line with the guidelines provided by the Curriculum Development and Research Division (CRDD) of the Ghana Education Service (GES). The CRDD (2007) observed in the SHS core mathematics syllabus that although problem solving has not been made a topic by itself in the syllabus since nearly all topics include solving word problems as activities, "it is hoped that teachers and textbook developers will incorporate appropriate problems that will require mathematical thinking rather than mere recall and use of standard algorithms" (p. iv). Indeed, the syllabus puts a lot of emphasis of on application of knowledge.

The two profile dimensions that have been specified for teaching, learning and testing at the SHS level are "knowledge and understanding", which accounts for just about $30 \%$ of the syllabus and "application of knowledge, which accounts for the remaining 70\% or so. Each of the dimensions has been given a percentage weight that should be reflected in teaching, learning and testing. The weights indicated for the dimensions, show the relative emphasis that the teacher should give in the teaching, learning and testing processes at Senior High School (CRDD, op. cit).

The CRDD points out further that it has been realized that schools still teach low ability thinking skills of knowledge and understanding and ignore the higher ability thinking skills: 
Instruction in most cases has tended to stress knowledge acquisition to the detriment of the higher ability behaviours such as application, analysis, etc. The persistence of this situation in the school system means that students will only do well on recall items and questions and perform poorly on questions that require higher ability thinking skills such as application of mathematical principles and problem solving.... (CRDD, 2007, pp.viii-ix).

The study was therefore a small step towards providing information on the level of implementation by senior high schools mathematics teachers of the guidelines provided by the CRDD on the teaching of problem solving and application in mathematics.

The main research question that guided the enquiry was "to what extent can students in Senior High School Form 1 solve real-life problems using mathematical ideas?" Following the above review of the literature on problem solving generally and application of mathematical ideas to real-life problems in particular, it was hypothesised that the students would perform better on "routine" mathematical exercises (mainly involving figures) than on exercises based on real life problems. Thus the null hypothesis $\left(\mathrm{H}_{0}\right)$ and alternative hypothesis $(\mathrm{H} 1)$ for the quasi-experimental study were defined as follows: $\mathrm{H}_{0}: \mu 1=\mu 2$; and $\mathrm{H}_{1}: \mu 1>\mu 2 \quad$ (one tail); (where $\mu_{1}$ and $\mu_{2}$ are respectively the population mean scores on routine mathematical tasks and tasks based on real-life problems requiring the use of mathematical concepts).

\section{Methodology}

Population and sample: The target population for the study was all SHS Form 1 students in public and private senior high schools in the Accra Metropolis of Ghana. The SHS system provides further education to eligible junior high school pupils. The objective is to help equip students with skills and knowledge either for direct entry into the world of work or for further education. This explains why there is a lot of emphasis on the application of knowledge in the core mathematics syllabus. There are twenty-eight senior high schools in Accra, the capital of Ghana. Of these, four are international senior secondary schools which do not run the SHS programme. Instead these schools follow the International General Certificate of School Certificate (IGCSE) curriculum as the students are mainly children of expatriates and children of Africans in the Diaspora who are sent to these schools to study towards the IGCSE so they can pursue the General Certificate of education (GCE) Advanced Level course and enter universities abroad. The target population did not include these international schools.

A simple random sampling method was used to select two schools from the twenty-four schools whose Form 1 students constituted the target population. The schools selected were both mixed schools so in each of them, fifteen boys and fifteen girls were selected at random for the study. Thus, in all thirty boys and thirty girls took part in the study. The selection was done by final year Bachelor of Education Mathematics undergraduate teacher-trainees from the University of Cape Coast who were at the time of the study on internship in the schools. The teacher-trainees were trained by the researcher on how to select the participants for the study as well as how to collect data from same. The researcher was the leader of a team of lecturers appointed to assess the lessons of the teacher-trainees and write reports on the latter.

Data Collection: Data for the study were collected using three instruments - a "routine" test made up of items on percentages (mainly in figures), a piece of short-writing in which the participants explained briefly how they would solve a real-life problems involving percentages and an interview schedule. Each of the first two instruments consisted of a single sheet with items and spaces provided for answers on both pages of the sheet. Each routine test item had a corresponding "short -writing" item on which the participants were required to explain how they would solve a problem in a real-life situation. For example, one of the 
items in the routine test was "what is $1.2 \times 25 \%$ ?" The corresponding short-writing item was "the original rate of interest on a hire purchase of a television set was $25 \%$. The rate has just been increased. If the new rate represents an increase of $20 \%$ of the original rate, explain briefly how you will find out how much more or how much less the new cost of the television is." In all, there were ten routine test items and ten corresponding short-writing items.

The instruments were piloted in one of the senior high schools in Accra. The reliability analyses of the routine test and the writing task yielded an overall reliability coefficients of 0.89 and 0.83 respectively which indicated very high internal consistency of the instruments (Cline, 1999). The results of the pilot study also helped the researcher to revise some of the items. Furthermore, senior colleagues in both Adults Learning Mathematics (ALM) and the University of Cape Coast provided useful feedback on the items and this helped to enhance the validity of the items.

Data for the actual study were collected between June and August 2008 when the teachertrainees were on internship in the schools in the Accra Metropolis. The tasks were administered by the teacher-trainees (who had been trained for the purpose) in the selected schools. Participants were told not to write their names on the sheets, albeit the latter had been coded for reference purposes. Participants were given 1 hour to complete both task sheets. The first task sheet (which contained the "routine" task) was collected after thirty minutes and the participants began the second task sheet immediately after the first task sheet had been collected. This was done to ensure that the participants did not spend too much time on one task sheet at the expense of the other. The completed sheets were put in sealed envelopes and made ready for collection by the researcher. The researcher later visited the schools and collected the completed task sheets.

A week after the completed task sheets had been collected from both schools, the researcher visited the schools again to conduct interviews. The teacher-trainees kept a 'coded' list of the participants and this helped with the selection of participants for the interviews. Participants who were interviewed were selected on the basis of the differences between their scores on the two tasks. In each school, two boys and two girls were selected randomly from those with a difference of 3 marks or more between their scores on the two tasks, and one boy and one girl were selected randomly from those with no difference between their scores on the two tasks. Thus in all, six boys and six girls were interviewed. The interviews were about how the students found the items in both the routine and the short-writing tasks. The interviewees narrated how they went about the tasks and which of the items they found difficult and which ones they found easy. All interviews were recorded with the consent of the interviewees, each of whom was delighted to hear his or her voice on tape when the interviews were played back to them.

\section{Results}

Each of the tasks carried a maximum of 10 marks as each correct respond was awarded 1 mark. The participants' pairs of scores on the tasks were separated for comparison purposes. To investigate the differences between the two means (for the tasks) within groups (e.g. School A boys' mean score in routine task versus School A boys' mean score in short-written task), the t-test of dependence for difference in means of two samples was used, whereas the t-test of independence was used to investigate differences of mean scores between groups (e.g. School A boys' means score on routine task versus School A girls' mean score) (Rosnow \& Rosenthal, 2005). Initial analysis revealed no differences between the mean scores of the two schools in either task. Further analysis was therefore done on the differences between the means for the tasks within the two schools. Tables 1 gives the distribution of the scores (including means and standard errors of the differences between the pairs of scores) in the two schools. 
Table 1 Boys' scores in the routine and short-writing task in School A

\begin{tabular}{lllllllll}
\hline Score & $\mathbf{5}$ & $\mathbf{6}$ & $\mathbf{7}$ & $\mathbf{8}$ & $\mathbf{9}$ & $\mathbf{1 0}$ & Mean & t-value \\
\hline Routine (Frequency) & 0 & 0 & 3 & 4 & 3 & 5 & 8.7 & \\
Short-writing (Frequency) & 0 & 5 & 5 & 4 & 1 & 0 & 7.1 & 6.8085 \\
\hline
\end{tabular}

It can be inferred from the above table that the mean scores for the routine and short-writing tasks for the 15 boys in school in School A were 8.7 and 7.1 respectively. The standard error of the differences between the students' scores on the two tasks was 0.2350 . The calculated $t$ -value of 6.8085 shows a significant difference between the two sample means at the $0.1 \%$ level. Thus the boys who participated in the study from School A achieved significantly higher on the routine task that they did on the short-writing task.

Table 2 Girls' scores in the routine and short-writing task in School A

\begin{tabular}{lllllllll}
\hline Score & $\mathbf{5}$ & $\mathbf{6}$ & $\mathbf{7}$ & $\mathbf{8}$ & $\mathbf{9}$ & $\mathbf{1 0}$ & Mean & t-value \\
\hline Routine (Frequency) & 0 & 1 & 4 & 4 & 2 & 3 & 8.1 & \\
Short-writing (Frequency) & 2 & 5 & 4 & 4 & 0 & 0 & 6.7 & 6.5026 \\
\hline
\end{tabular}

The above table gives the mean scores for the routine and short-writing tasks for the 15 girls in school in School A. The sample means were 8.1 and 6.7 respectively and the standard error of the differences between the students' scores on the two tasks was 0.2153 . The calculated tvalue was 6.5026 and this also showed that the difference between the two means was significant at the $0.1 \%$ level. Thus in School A, the girls also achieved significantly higher on the routine task that they did on the short-writing task.

Table 3

Boys' scores in the routine and short-writing task in School B

\begin{tabular}{lllllllll}
\hline Score & $\mathbf{5}$ & $\mathbf{6}$ & $\mathbf{7}$ & $\mathbf{8}$ & $\mathbf{9}$ & $\mathbf{1 0}$ & Mean & t-value \\
\hline Routine (Frequency) & 0 & 0 & 3 & 7 & 2 & 3 & 8.3 & \\
Short-writing (Frequency) & 0 & 4 & 6 & 4 & 1 & 0 & 7.1 & 5.2817 \\
\hline
\end{tabular}

Table 3 shows the distribution of scores for boys in School B. According to the table, the boys' means scores for the routine and short-writing tasks were 8.3 and 7.1 respectively and the corresponding standard error was 0.2272. Here too, the difference between the two means was significant at the $0.1 \%$ level, with a t-value of 5.2817.

Table $4 \quad$ Girls' scores in the routine and short-writing task in School B

\begin{tabular}{lllllllll}
\hline Score & $\mathbf{5}$ & $\mathbf{6}$ & $\mathbf{7}$ & $\mathbf{8}$ & $\mathbf{9}$ & $\mathbf{1 0}$ & Mean & t-value \\
\hline Routine (Frequency) & 0 & 2 & 3 & 4 & 4 & 2 & 8.1 & 4.2824 \\
Short-writing (Frequency) & 1 & 6 & 7 & 1 & 0 & 0 & 6.5 & \\
\hline
\end{tabular}

The distribution of the scores for the girls in School B is given in the above table. The girls scored a mean of 8.1 on the routine task and a mean of 6.5 on the short-writing task. As it was in the case of the three groups above, there was a statistically significant difference between the two means. The calculated t-value for the data was 4.2824 and this also showed that the difference between the two means was statistically significant at the $0.1 \%$ level.

To verify the above results, all the 60 pairs of scores were analysed using the paired sample ttest as well as the Pearson's product moment correlation coefficient. The former was used to check earlier results and the latter was used to determine how much of the variance in the short-written test was explained by the variations in the routine task scores. The paired sample t-value calculated using all the 60 pairs of scores was 12.6087 indicating that the 
participants' competencies in routine tasks were far superior to their competencies in applying their knowledge and skills in classroom mathematics to solve real life problems.

The Pearson's product moment correlation between the routine and the short-writing test for all the 60 pairs of scores was $0.73\left(\mathrm{R}^{2}=0.53\right)$. The $\mathrm{R}^{2}$ value shows that 53 percent of the variations in the short-writing scores can be explained by the variations in the routine scores. The interview data arguably provided some limited explanation for some of the unexplained 47 percent of the variations between the two sets of scores.

As mentioned above, the interviews were recorded with the permission of the interviewees. The interviews were transcribed and studied for themes. The main themes that emerged were the perceived differences between the routine task items and their corresponding shortwriting task items and the language requirements of the short-writing task. One of the participants said:

The first test [routine task] was straightforward because we were given the numbers but the other test [short-writing] was not simple at all....Anyone who didn't understand the English would find it difficult.

Asked whether the two tasks were similar, this interviewee replied that only a few of them were similar and that they were two different tasks. Another interviewee gave a specific example and explained his answer:

The question about the increase in interest rate, I said the answer was $45 \%$ but after the test my friends said that was a wrong answer...I don't understand why because increase means add but they said it was wrong....

The item the interviewee was talking about required the participants to explain how they would find the new cost of a television set bought on a hire purchase. The original interest rate was $25 \%$ and the new rate was an increase of $20 \%$ of the original rate. The success rate of this question was item was $31.7 \%$, yet the success rate of its corresponding routine item " 1.2 x $25 \%$ " was $88.3 \%$ !

The interviewee in question also said that the English was "hard to write". Asked whether he understood all the questions in the short-writing task, this interviewee answered in the affirmative implying that although he understood the questions he found the writing of the answers was "hard". This particular interviewee scored 8 in the routine task exercise but scored 5 in the short-writing task.

Nearly all the interviewees were of the view that the routine task was not only easier than the short-writing task but it was different from the latter. This is interesting because there was a moderate to high positive correlation between the students' scores on the two tasks yet they seemed to think that the tasks were different. Admittedly, the correlation appeared high because the scores on the short-writing exercise were consistently lower than those on the routine task but at least one would have expected the connections between the two tasks to have contributed to the high correlation. This observation seems to suggest that if the students had made the connections between the two tasks easily, their scores on the shortwriting task would have been higher and there would not have been any significant differences in their mean scores on the two tasks. Even the four interviewees whose scores were the same on both tasks did not easily find the connections between the items on the routine task and those on the short-writing tasks. This finding suggests that the students' performance on the short-writing depended on other factors in addition to their ability to do routine calculations. Their inability to make the connections between the two tasks has important implications for the teaching and learning of mathematics and these and the other findings are discussed below. 


\section{Discussion}

The findings of the study confirm those reported by other researchers and authors on students' poor application of classroom routine mathematics to real-world situations (Cai and Silver, 1995; Verschaffel \& de Corte, 2000). Students in the present study failed to make the connections between classroom mathematics and their real life applications and a number of reasons have been put forward to explain the difficulty they may have had in applying mathematical concepts to real- life situations.

It can be argued that, in order to learn the application of mathematical concepts successfully, one needs to link the demands of the application tasks to the cognitive processes involved. One of these cognitive processes is information processing which plays a key role in learners' understanding of which aspects of the information provided in the task would be helpful in answering an application question and which would not be so helpful. The students' difficulty in linking classroom mathematics to real-life mathematics or functional mathematics can be explained in terms of the quality of instructions they have received regarding problem solving.

The information processing approach to identifying problem-solving processes focuses on the sequential steps of cognitive demands required in solving a mathematical problem. Many classification schemes for problem-solving processes are derived from Polya's conception of mathematics problem solving as a four-phase heuristic process: understand the problem, devise a plan, carry out the plan, look back and check (Polya, 1973). While these broad processes cover most aspects of problem solving, it is the teacher's role to provide sufficient detail and guidance to students to enable the latter to improve their problem-solving skills. A number of errors made by the participants in this research resulted from the students not looking back and checking the reasonableness of their answers.

Some participants simply made use of the figures in the text anyhow without checking to see if the answers made sense. For example one of the items read: "Last Saturday, John polished $30 \%$ of all the chairs in his restaurant and his daughter, Mary polished $20 \%$ of the chairs. How many days will it take both of them to clean all the chairs in the restaurant if they work at the same rate?" 27 out of the $60(45 \%)$ of the students gave an answer of 50\%; and 3 students said it would take 50 days! If the students who thought it would take 50 days to do the job had considered what percentage of the work would be done in one day (i. e. $2 \%$, using their own answer as a check), they probably would have changed their answer. In any case, it can be argued, as far as the attempt made by the students to solve the problem is concerned, that at least one of the four-phase heuristic stages proposed by Polya was absent in the above examples. At worst, many students did not understand the problem; at best many of them did not check the sensibleness of their answers.

Schoenfeld (1983) developed a model based on findings from research by informationprocessing theorists. His model incorporated Polya's structure and described mathematical problem solving in five episodes: reading, analysis, exploration, planning/implementation and verification. Using Schonfeld's model, one can say that the student may have read the items but lacked the ability to analyse them to find out which of the pieces of information could be combined to produce a successful outcome by way of a solution. It may well be that the students failed to explore the various ways in which those pieces of information could be used to arrive at a meaningful solution or indeed failed to evaluate their solutions. Again here too, at best they failed to evaluate and at worst, they simply did not read the item well enough to extract the most appropriate information.

Still on information processing approaches to problem solving, Mayer and Hegarty (1996) examined mathematics problem solving in terms of four components: translating, integrating, planning and executing. They hypothesised how expert problem solvers use different 
strategies from novice problem solvers in these four components. This model would suggest that those students who had scored 3 marks (or more) less in the short-writing task than they did in the routine were novices who could not successfully translate the short-writing task items into routine tasks items or who could not execute their plans successfully if they really understood the items. The students' levels of expertise in following problem solving strategies may have accounted for some of the unexplained variations exposed by the correlation between the students' scores on the two tasks.

In all the above models, the information processing theorists identify the stages of problem solving so that these can be used to teach students how to approach a problem and what to do when they encounter difficulties. In particular, these problem-solving stages can serve as useful prompts for students to monitor and evaluate their own thought processes (Wu \& Adams, 2006). Indeed, without clearly identified problem-solving stages, the problemsolving activities carried out in the classroom can be somewhat ad hoc and disorganised. Approaching problem solving in a systematic way using steps defined through the information processing approach can help students acquire skills that are transferable to a wider range of problems ( $\mathrm{Wu} \&$ Adams, op cit).

Perhaps the other thing to consider in this study is the use of language. In translating mathematical word problems into appropriate mathematical models, learners need the appropriate level of competence in the language used. A number of the interviewees mentioned language as one of the things that made the short writing items more difficult than the routine items. They said they found it difficult to start writing the answer and that is why they either could not complete the task or were not able to write answers that made sense. It is possible that some students even found it difficult to read the items with understanding. In other words, some students would have found it difficult to write the items in their own words to demonstrate understanding. There were indeed, many examples in the students' solutions that demonstrated that their failure to solve some of the problems correctly was due to an incomplete or incorrect understanding of the problem situation. Whimbey and Lochhead (1991) rightly place a strong emphasis on the importance of understanding a problem. They observe:

Good problem solvers take great care to understand the facts and relationships in a problem fully and accurately .... Quite often poor problem solvers could have found out the solution if they had been more careful. But poor problem solvers have not learned how important it is to try to be completely accurate in understanding all the ideas of a problem. (p.26)

In normal teaching practice, word problems are often the only means of providing students with a basic sense experience in mathematization. It is therefore imperative that learners have the required level of competence in the language used to enable them to understand the problem in the first place.

A number of approaches can be used to address students' lack of understanding mathematical word problems either due to language difficulties or due to what Schonfeld (1991) refers to as a "suspension of sense-making", a situation in which students tend to ignore relevant familiar aspects of reality and exclude real-world knowledge from their mathematical problem solving. Due to lack of space, only two of these approaches are presented here by way of recommendations of the study.

First, there is a need to identify a set of goals for mathematics education that moves the curriculum away from the traditional emphasis on decontextualised mathematical knowledge towards the processes of problem solving and doing mathematics. Under this "holistic" approach, the traditional mathematics content strands should be subsumed under the broader approach of problem solving. The document, Principles and Standards for School Mathematics (NCTM, 2000), for example, stresses this holistic approach to the teaching and 
learning of mathematics. It is important to point out that the CRDD (2007) also acknowledges this approach because it advises that teachers of secondary school mathematics must "select a practical mathematical problem for each lesson [and that] the selection must be made such that students can use knowledge gained in the previous lesson and other types of information not specifically taught in class" (p.viii, my emphasis). As mentioned elsewhere in this paper, the CRDD also gives to the profile dimension "application of knowledge" a weighting which is nearly two-and -a half times the profile dimension "knowledge and understanding" (CRDD, op. cit)

The second recommendation is related to the theory of Realistic Mathematics Education (RME) developed in the Netherlands (De Lange, 1996; Freudenthal, 1991; Gravemeijer, 1999). Over the past 30 years the RME has gathered support from around the world (Hoyles et al, 2002; OECD, 2003; Swan, 2005; Tomlinson, 2004). In RME, learning mathematics means doing mathematics, and solving everyday life problems is an essential part of the theory. Another key principle is that students should be given the opportunity to reinvent mathematical concepts. The heart of this reinvention process involves mathematizing activities in problem situations that are experientially real to students. If students are to be given the opportunity to reinvent mathematical concepts either individually or collectively (e. g. in whole-class discussions focusing on a conjecture, an explanation or justification) then it follows that the teaching and learning process should be highly interactive.

Two important principles underlie RME - i) mathematics must be connected to the realworld; and ii) mathematics should be seen as a human activity. In sum, the approach advocates the taking of the real world into the mathematics classroom. Related to this approach is the approach that takes mathematics out of the classrooms and into the real-world (e.g. Bonotto, 2007). The latter approach takes mathematics to the real-world, in contrast to RME that takes the real-world to mathematics. The emphasis is to solve real-world problems using mathematics, rather than to teach mathematical concepts using real-world problems. Either way, both approaches encourage communication between the mathematics classroom and the real-world. This should be an important goal of mathematics education for every teacher of mathematics.

\section{Conclusion}

Establishing connections between classroom mathematics activities and everyday-life experiences still involves mainly word problems. Research has documented that the practice of word problem solving in school mathematics actually promotes in students a "suspension of sense-making" and the exclusion of realistic considerations. Several studies point to two reasons for this lack of use of everyday-life knowledge. The first one is to do with factors relating to the stereotypical nature of the textbook problems used by teachers. In some textbooks, problem solving, according to Wyndham and Säljö (1997), “ is made [so] routine in stereotypical pattern [that] in many cases it is easier for the student to solve the problem than to understand the solution and why it fits the problem" (p.364). Surely, the development of mathematical problem-solving, skills, beliefs, and attitudes should not emanate from textbooks or from a specific part of the curriculum only. It should permeate the entire curriculum so that the study of mathematics becomes simply the study of problem solving strategies as proposed rightly by RME theorists.

Secondly, there are presentational or contextual factors associated with practices, environments and expectations related to the classroom culture of mathematical problem solving (Lave, 1988). As Gravemeijer (1997) rightly points out, "in general, the classroom climate is one that endorses separation between school mathematics and every-day life reality" (p.389). It is therefore important that teachers of mathematics create the right 
environments in their classrooms to enable problem solving to flourish. They can do this by embracing the goals of mathematics education espoused in 'interactive' mathematics education studies and reports (e.g. Swan, 2005).

As far as the present study is concerned, teachers of mathematics should embrace the goals of mathematics education highlighted in the SHS mathematics curriculum. This recommendation is important not only because mathematics teachers' beliefs about the goals of mathematics education have considerable influence on their practice, but because such beliefs influence learners' conception about what mathematics education is all about. Finally, the present study is a small study in terms of the number of schools and the number of students involved and the findings cannot in anyway be generalised beyond the Accra Metropolis.

Regarding recommendation for further research, there is a need to conduct a much bigger study involving many schools in many regions of the country in order to throw more light on whether or not teachers of secondary school mathematics in Ghana have heeded the advice given by the CRDD regarding the teaching of mathematics to reflect the weighting of the profile dimension "application of knowledge" of mathematics.

\section{References}

Bonotto, C. (2007). How to replace the word problems with activities of realistic mathematical modeling. In W. Blum, P. Galbraith, M. Niss, H. W. Henn (Eds) Modelling and Applications in Mathematics Education (pp. 185-192). New ICMI Studies Series no. 10. New York: Springer.

Cai, J., \& Silver, E. A. (1995). Solution processes and interpretations of solutions in solving division-with-remainder story problems: Do Chinese and U.S. students have similar difficulties? Journal for Research in Mathematics Education, 26, 491- 497.

Cline, P. (1999). The handbook of psychological testing ( $2^{\text {nd }}$ edition). London: Routledge

CRDD (2007). Teaching syllabus for senior high school mathematics. Accra: Curriculum Research and Development Division. Ghana Education Service

De Lange, J. (1996). Using and applying mathematics in education. In A. J. Bishop, K. Clements, C. Keitel, J. Kilpatrick, \& C. Laborde (Eds.), International handbook of mathematics education (pp. 49-98). Dordrecht, The Netherlands: Kluwer.

DfES (2005). 14-19 Education and skills: implementation plan. London: DfES

DIUS (2007). World class skills: implementing the Leitch review of skills in England. London: DIUS

Fletcher J.A. (2001). Mathematics education and continuous assessment in Ghanaian secondary schools. Continuous assessment of what? Journal of the Mathematics Connections 2 (7-11)

Freudenthal, H. (1991). Revisiting mathematics education. China lectures. Dordrecht: Kluwer.

Gravemeijer, K. (1997). "Commentary solving word problems: A case of modelling", Learning and Instruction, 7, 389-397.

Hoyles, A., Wolf, A.,Molyneux-Hodgson, S. and Kent, P (2002). Mathematical skills in the workplace. London: Institute of Education.

Hughes, M., Desforges, C., and Mitchell, C (2000). Numeracy and beyond: applying mathematics in the primary School. Milton Keynes: Open University Press 
Lave, J. (1988). Cognition in practice: mind, mathematics and culture in everyday life, Cambridge:Cambridge University Press.

Leitch, S. (2006). Prosperity for all in the global economy - world class skills: final report. London: The Stationery Office

Mayer, R. E., \& Hegarty, M. (1996). In R. J. Sternberg \& B.-Z. Talia (Eds.), The nature ofmathematical thinking. Mahwah, NJ: Lawrence Erlbaum.

National Council of Teachers of Mathematics (NCTM) 2000. Principles and Standards for School Mathematics. Reston, VA: National Council of Teachers of Mathematics.

Nunes, T., Schliemann, A.D. \& Carraher, D.W. (1993). Mathematics in the streets and in schools. Cambridge, U.K: Cambridge University Press.

OECD (2003). The PISA 2003 assessment framework. Paris: OECD.

Polya, G. (1973). How to solve it: a new aspect of mathematical method. Princeton, NJ: Princeton University Press

QCA (2007). Functional skills draft standards. www.qca.org.uk/qca_6066.aspx accessed at 11.15am on 20th December, 2008

Rosnow, R. L. and Rosenthal, R. (2005). Beginning behavioural research: a conceptual primer. ( $5^{\text {th }}$ edition). Englewoods Cliff, NJ: Pearson/Prentice Hall

Royal Society (2008). A 'state of the nation' report on the participation and attainment of 14-19 year olds in science and mathematics in the UK, 1996-2007. London: The Royal Society

Säljö, R., \& Wyndham, J. (1990). Problem solving, academic performance and situated reasoning: A study of joint cognitive activity in the formal setting. British Journal of Educational Psychology, 60, 245-254.

Schoenfeld, A. H. (1983). Episodes and executive decisions in mathematical problem solving. In R. Lesh \& M. Landau, M. (Eds.), Acquisition of mathematics concepts and processes (pp. 345-395). New York: Academic.

Schoenfeld, A. H. (1991). On mathematics sense making: An informal attack on the unfortunately divorce of formal and informal mathematics. In J.F. Voss, D.N. Perkins and J.W. Segal (Eds.), Informal reasoning and education (pp. 311-343). Hillsdale, NJ: Lawrence Erlbaum Associates.

Smith, A. (2004). Making mathematics count. The report of Professor Adrian Smith's inquiry into Post-14 mathematics education. London: The Stationery Office Limited

Swan, M. ( 2005). Improving learning in mathematics: strategies and challenges. London: Department of Education and Skills Standards Unit

Tomlinson, M. (2004). 14-19 Curriculum and qualifications reform. Final report of the working group on 14-19 Reform. London: Department for Education and Skills

Verschaffel, L., Greer, B. \& de Corte E. (2000). Making sense of word problems. Lisse, Switzerland: Swets \& Zeitlinger

Whimbey, A., \& Lochhead, J. (1991). Problem solving and comprehension (5th ed.) Hillsdale, NJ: Lawrence Erlbaum. 
Wu, M., \& Adams, R. (2006). Modelling Mathematics Problem Solving Item Responses Using a Multidimensional IRT Model. Mathematics Education Research Journal 18(2), 93-113

Wyndhamn, J., \& Säljö, R. (1997). "Word problems and mathematical reasoning - A study of children's mastery of reference and meaning in textual realities", Learning and Instruction, 7, 361-382. 